Jurnal Ilmiah Matematika dan Pendidikan Matematika (JMP)

Vol. 9 No. 2, Desember 2017, hal. 75-86

ISSN (Cetak) : 2085-1456; ISSN (Online) : 2550-0422; https://jmpunsoed.com/

\title{
PENERAPAN CONFIGURAL FREQUENCY ANALYSIS (CFA) \\ UNTUK MENENTUKAN KARAKTERISTIK USER DAN NON USER \\ MOTOR X DI KOTA CIREBON \\ (Studi Kasus PT. XYZ)
}

\author{
Muhamad Iqbal Mawardi \\ Departemen Statistika, Universitas Padjadjaran \\ 1992iqbal@gmail.com \\ Bertho Tantular \\ Departemen Statistika, Universitas Padjadjaran \\ Resa Septiani Pontoh \\ Departemen Statistika, Universitas Padjadjaran
}

\begin{abstract}
PT. XYZ has a role as the main dealer of motor $X$ in West Java with marketing area in three cities: Bandung, Bekasi and Cirebon. The company survey always held every year about Brand Awareness \& Image to users and non user motor $X$ to know the characteristics of consumers. Based on the company report survey there was a decrease in the indicators of Top Of Mind Unit in Cirebon City for the user of $30.8 \%$ and for non users of $9.8 \%$. This study aims to determine the characteristics that cause the decline of the Top Of Mind Unit based on the configuration of user characteristics and non user motor $X$ in Cirebon City by using Configural Frequency Analysis (CFA). From the results of data analysis can be seen that there are three configurations of user characteristics and non users that deviate from the base model is formed. These three configurations can be considered in determining the marketing strategy to maintain and improve the Top Of Mind Unit in Cirebon City.
\end{abstract}

Keywords: Brand Awareness, Top Of Mind, Configural Frequency Analysis (CFA), Base Model.

ABSTRAK. PT. XYZ berperan sebagai main dealer motor X di Jawa Barat dengan wilayah pemasaran di tiga Kota yaitu Bandung, Bekasi dan Cirebon. Dalam satu tahun perusahaan selalu mengadakan survey mengenai Brand Awareness \& Image terhadap user dan non user motor $\mathrm{X}$ dengan tujuan mengetahui karakteristik konsumen. Laporan dari hasil survey perusahaan menunjukan terjadi penurunan pada indikator Top Of Mind Unit di Kota Cirebon untuk user sebesar 30,8\% dan untuk non user sebesar 9,8\%. Penelitian ini bertujuan untuk mengetahui karakteristik yang menyebabkan terjadinya penurunan Top Of Mind Unit berdasarkan konfigurasi dari karakteristik user dan non user 
motor X di Kota Cirebon dengan menggunakan Configural Frequency Analysis (CFA). Dari hasil analisis data dapat diketahui bahwa terdapat tiga konfigurasi dari karakteristik user dan non user yang menyimpang dari base model yang terbentuk. Ketiga konfigurasi tersebut dapat dijadikan bahan pertimbangan dalam menentukan strategi pemasaran untuk mempertahankan dan meningkatkan Top Of Mind Unit di Kota Cirebon.

Kata Kunci: Brand Awareness, Top Of Mind, Configural Frequency Analysis (CFA), Base Model.

\section{PENDAHULUAN}

PT. XYZ sebagai main dealer sepeda motor $\mathrm{X}$ di Jawa Barat selalu berusaha untuk mempertahankan dan meningkatkan loyalitas konsumen yang telah diraih dengan cara mengadakan survey setiap tahun mengenai brand awareness \& image terhadap user (pengguna sepeda motor) dan non user (calon pengguna sepeda motor) $\mathrm{X}$ untuk mengetahui karakteristik konsumen. Berdasarkan laporan divisi Customer Knowledge and Management, terjadi penurunan Top Of Mind Unit yang merupakan salah satu indikator dalam menentukan Brand Awareness \& Image sepeda motor X, yaitu untuk user sebesar $30,8 \%$ dan untuk non user sebesar 9,8\%. Untuk mengantisipasi kondisi penurunan Top Of Mind Unit di Kota Cirebon, P.T. XYZ memerlukan metode analisis yang tepat dalam menentukan karakteristik user dan non user sepeda motor X tersebut.

Dalam penelitian ini, metode analisis yang digunakan adalah Configural Frequency Analysis (CFA) untuk melihat apakah suatu karakteristik yang terbentuk dari konfigurasi tertentu sesuai atau tidak dengan apa yang diharapkan.

\section{METODE PENELITIAN}

Dalam melakukan analisis dengan menggunakan metode Configural Frequency Analysis (CFA), data yang digunakan merupakan hasil survey P.T. XYZ mengenai karakteristik Brand Awareness \& Image di Kota Cirebon terhadap 190 responden. Pengambilan sampel dilakukan dengan menggunakan metode multinomial sampling. Terdapat empat faktor yang akan dilihat keterkaitannya: Top Of Mind (merk yang paling diingat) sepeda motor $\mathrm{X}$ yang dibagi menjadi dua kategori, yaitu: $\mathrm{X}$ dan kompetitor; pekerjaan yang dibagi menjadi tiga kategori, yaitu: pelajar/mahasiswa, karyawan (PNS/Swasta), lainnya (wiraswasta); 
pengeluaran per bulan yang dibagi menjadi dua kategori, yaitu: kurang dari atau sama dengan dan lebih dari Rp. 1.250.000,00; dan pengguna motor yang dibagi menjadi dua kategori, yaitu: user (pengguna sepeda motor) dan non user (calon pengguna sepeda motor).

\subsection{Configural Frequency Analysis}

Configural Frequency Analysis (CFA) adalah suatu metode yang digunakan untuk mengidentifikasi pola (konfigurasi) variabel kategori apakah terjadi ketidakcocokan (discrepancies) dengan apa yang telah diekspektasikan sebelumnya atau tidak. Ketidakcocokan (discrepancies) terjadi jika:

1. suatu peristiwa yang terjadi lebih besar daripada yang diekspektasikan atau, dengan kata lain, lebih sering terjadi (CFA type), dan

2. suatu peristiwa yang terjadi lebih kecil daripada yang diekspektasikan atau, dengan kata lain, lebih jarang terjadi (CFA antitype).

Pada dasarnya, metode $C F A$ tidak memfokuskan pada apakah suatu model akan cocok dengan data atau tidak karena analisis ini hanya ingin memperlihatkan fenomena atau konfigurasi yang memang secara signifikan kejadiannya jauh dari apa yang telah diharapkan dari model yang terbentuk.

Terdapat lima langkah pengujian dengan menggunakan $C F A$ :

1. Pemilihan base model

2. Pemilihan konsep penyimpangan dari suatu model.

3. Menentukan tes signifikansi.

4. Menentukan estimasi frekuensi harapan.

5. Interpretasi type dan antitype.

\subsection{Base Model Log Linier}

Base model log linier dapat menjelaskan asumsi teoritis bahwa, pada model log linier, semua variabel mempunyai status yang sama sebagai suatu respon (Agresti, 1996). Untuk melihat adanya interaksi antar prediktor, pengujian main effect antar prediktor dapat dilakukan. Jika terdapat type atau antitype artinya memang terdapat interaksi antar prediktor. Model log linier untuk melihat 
ada atau tidaknya interaksi antar prediktor (Von Eye, 2002) adalah sebagai berikut:

$$
\log E\left(Y_{i j k}\right)=\mu+A_{i}+B_{j}+C_{k}
$$

dengan $E\left(Y_{i j k}\right)=$ ekspektasi setiap sel.

$\mu \quad=$ intercept atau constant atau rata-rata umum

$A_{i} \quad=$ Efek utama faktor A (Pekerjaan) pada kategori ke- $i$ ( $i=1$

(Pelajar/Mahasiswa), $i=2$ (Karyawan), $i=3$ (Lainnya))

$B_{j} \quad=$ Efek utama faktor B (Pengeluaran per bulan) pada kategori ke- $j$

$(j=1(\leq$ Rp. 1.250.000,00), $j=2(>$ Rp. 1.250.000,00))

$C_{j} \quad=$ Efek utama faktor $\mathrm{C}$ (Pengguna Sepeda Motor) pada kategori ke- $k$ ( $k=1$ (User), $k=2$ (Non User))

Apabila terdapat interaksi antar prediktornya maka model log linier untuk data (Von Eye, 2002) adalah sebagai berikut:

$$
\log E\left(Y_{i j k l}\right)=\mu+A_{i}+B_{j}+C_{k}+D_{l}+A B_{i j}+A C_{i k}+B C_{j k}+A B C_{i j k} .
$$

dengan $E\left(Y_{i j k l}\right)=$ frekuensi diharapkan setiap sel.

$\mu \quad=$ intercept atau constant atau rata-rata umum

$A_{i} \quad=$ Efek utama faktor A (Pekerjaan) pada kategori ke- $i$ ( $i=1$

(Pelajar/Mahasiswa), $i=2$ (Karyawan), $i=3$ (Lainnya))

$B_{j} \quad=$ Efek utama faktor B (Pengeluaran per bulan) pada kategori ke- $j$ $(j=1(\leq$ Rp. 1.250.000,00), $j=2$ (>Rp. 1.250.000,00))

$C_{j} \quad=$ Efek utama faktor $\mathrm{C}$ (Pengguna Sepeda Motor) pada kategori ke- $k$ ( $k=1$ (User), $k=2$ (Non User))

$D_{l} \quad=$ Efek utama faktor D (Top Of Mind) pada kategori ke- $l(l=1$ (motor $\mathrm{X}), l=2$ (Kompetitor))

$A B_{i j} \quad=$ interaksi tingkat ke- $i$ dan $j$ faktor $\mathrm{A}$ dan $\mathrm{B}$

$A C_{i k}=$ interaksi tingkat ke- $i$ dan $k$ faktor $\mathrm{A}$ dan $\mathrm{C}$

$B C_{j k}=$ interaksi tingkat ke-j dan $k$ faktor $\mathrm{B}$ dan $\mathrm{C}$ 
$A B C_{i j k}=$ interaksi tingkat ke- $i$, ke- $j$ dan $k$ faktor A, B dan $\mathrm{C}$

\subsection{Estimasi Frekuensi Ekspektasi}

Penaksiran terhadap ekspektasi frekuensi konfigurasi $\left(E\left(Y_{i j k l}\right)\right)$ digunakan dengan memanfaatkan metode Maksimum Likelihood. Fungsi dari distribusi multinomial dengan frekuensi sel $Y_{1}, \ldots, Y_{n}$ dan peluang tiap sel adalah $\theta_{1, \ldots,}, \theta_{n}$ dengan nilai $n$ yang telah ditentukan sebelumnya (Dobson, 1983) adalah sebagai berikut:

$$
f(y ; \theta \mid n)=n ! \prod_{i=1}^{N} \theta_{i}^{y_{i}} / y_{i} !
$$

dengan $n=\sum_{i=1}^{N} y_{i}$ dan $\sum_{i=1}^{N} \theta_{i}=1$.

Dengan menggunakan fungsi Log-Likelihood distribusi Multinomial, penaksir Maximum Likelihood parameter $\theta_{i}$ diperoleh dengan memaksimalkan fungsi Likelihood dengan constraint berupa Lagrange Multiplier. Maximum Likelihood Estimator dari parameter $\theta_{\mathrm{i}}$ untuk $\mathrm{E}\left(\mathrm{Y}_{\mathrm{i}}\right)$ adalah:

$$
\begin{aligned}
& \frac{\partial t}{\partial \theta_{i}}=\frac{Y_{i}}{\theta_{i}}-n=0 \\
& n \theta_{i}=Y_{i}
\end{aligned}
$$

sehingga diperoleh $E\left(Y_{\mathrm{ijk}}\right)=n \theta_{i . .} n \theta_{. \mathrm{j} .} n \theta_{. . \mathrm{k}}$ untuk distribusi multinomial di mana tanda titik menandakan variabel baris dan kolom independen dan $\mathrm{E}\left(\mathrm{Y}_{\mathrm{ijk}}\right)=\mathrm{n} \theta_{\ldots .} \mathrm{n} \theta_{\mathrm{ijk} .}$ jika terdapat interaksi diantara variabel tersebut.

\subsection{Uji Independensi Prediktor}

Dalam CFA base model, type dan antitype muncul ketika ada ketidakcocokan antara frekuensi observasi dan frekuensi ekspektasi. Untuk menguji independensi dari prediktor, main effect digunakan dengan hipotesis (Dobson, 1983) berikut:

$H_{0}: E\left(Y_{i j k}\right)=n \theta_{i . .} \theta_{. j .} \cdot \theta_{. \cdot k}$ (tidak terdapat asosiasi antar variabel prediktor)

$H_{1}: E\left(Y_{i j k}\right) \neq n \theta_{i . .} \theta_{. j .} \theta_{. . k}$ (terdapat asosiasi antar variabel prediktor) 
Statistik uji yang digunakan adalah chi-kuadrat dengan rumusan sebagai berikut:

$$
\chi^{2}=\sum_{i} \sum_{j} \sum_{k} \frac{\left(n_{i j k}-e_{i j k}\right)^{2}}{e_{i j k}}
$$

dengan: $n_{i j k}=$ frekuensi observasi pada baris ke- $i$, layer ke- $j$, kolom ke- $k$

$e_{i j k}=$ frekuensi ekspektasi pada baris ke- $i$, layer ke-j, kolom ke- $k$

\subsection{Uji Independensi Interaksi Prediktor dan Kriteria}

Untuk menguji independensi interaksi prediktor dan kriteria, main effect digunakan dengan hipotesis (Dobson, 1983) berikut:

$\mathrm{H}_{0}: \mathrm{E}\left(\mathrm{Y}_{\mathrm{ijkl}}\right)=\mathrm{n} \theta_{\ldots 1} \theta_{\mathrm{ijk} .}$ (tidak terdapat interaksi antar variabel prediktor)

$\mathrm{H}_{1}: \mathrm{E}\left(\mathrm{Y}_{\mathrm{ijkl}}\right) \neq \mathrm{n} \theta_{\ldots 1} \theta_{\mathrm{ijk} .}$ (terdapat interaksi antar variabel prediktor)

Statistik uji yang digunakan adalah chi-kuadrat dengan rumusan sebagai berikut:

$$
\chi^{2}=\sum_{i} \sum_{j} \sum_{k} \sum_{l} \frac{\left(n_{i j k l}-e_{i j k l}\right)^{2}}{e_{i j k l}}
$$

dengan: $n_{i j k l}=$ frekuensi observasi pada baris ke- $i$, layer ke- $j$, kolom ke- $k$, interaksi ke- $l$

$e_{i j k l}=$ frekuensi ekspektasi pada baris ke- $i$, layer ke-j, kolom ke- $k$, interaksi ke- $l$

\subsection{Metode Bonferroni untuk Melihat Signifikansi Konfigurasi}

Metode Bonferroni merupakan metode penyesuaian untuk $\alpha$. Penyesuaian dapat dilakukan dengan rumusan sebagai berikut:

$$
\alpha^{*}=\frac{\alpha}{T}
$$

dengan $T$ merupakan banyaknya konfigurasi

Untuk melihat signifikansi konfigurasi apakah terdapat penyimpangan dari base model yang terbentuk, maka dilakukan pengujian dengan hipotesis berikut: 
$H_{0}: E(N i)=E i$ (nilai frekuensi observasi sama dengan nilai frekuensi ekspektasi)

$H_{1}: E(N i) \neq E i$ (nilai frekuensi observasi sama dengan nilai frekuensi ekspektasi)

dengan statistik uji :

$$
z=\frac{N_{i}-E_{i}}{\sqrt{E_{i}}}
$$

di mana: $i=$ konfigurasi ke- $i$

$N_{i}=$ frekuensi observasi konfigurasi ke- $i$

$E_{i}=$ frekuensi ekspektasi konfigurasi ke- $i$

\section{HASIL DAN PEMBAHASAN}

Dalam penelitian ini, software R digunakan untuk menganalisis data. Pada langkah pertama, akan dilakukan analisis untuk melihat independensi diantara prediktor. Setelah itu, akan dilakukan analisis antara prediktor dan kriteria.

Analisis untuk prediktor dilakukan untuk melihat apakah terdapat asosiasi diantara variabel prediktor dengan hasil sebagai berikut:

Tabel 1. Tabel Hasil Statistik Uji Prediktor

\begin{tabular}{|l|r|}
\hline \multicolumn{1}{|c|}{ Statistik Uji } & \multicolumn{1}{|c|}{ Nilai } \\
\hline Chi Kuadrat & 48.20559 \\
\hline Derajat Bebas & 7 \\
\hline P-value & $3.406353 \mathrm{e}-11$ \\
\hline
\end{tabular}

Berdasarkan hasil output, nilai $p$-value $\leq \alpha$, yang berarti $H_{0}$ ditolak atau terdapat asosiasi diantara variabel prediktor.

Untuk uji independensi prediktor secara parsial, diperoleh hasil sebagai berikut: 
Tabel 2. Tabel Hasil Analisis Prediktor

\begin{tabular}{|r|r|r|r|r|r|r|}
\hline No & Konfigurasi & Ni & Ei & $\mathbf{Z}$ & P-Value & T/A \\
\hline 1 & 111 & 24 & 10,712576 & 4,059698 & 0.000024 & Type \\
\hline 2 & 112 & 4 & 4,476898 & 0,225391 & 0,410837 & \\
\hline 3 & 121 & 7 & 16,792687 & 2,389691 & 0,008431 & \\
\hline 4 & 122 & 4 & 7,017839 & 1,139185 & 0,127312 & \\
\hline 5 & 211 & 17 & 23,622604 & 1,362589 & 0,086506 & \\
\hline 6 & 212 & 2 & 9,872133 & 2,505456 & 0,006114 & \\
\hline 7 & 221 & 48 & 37,030028 & 1,802721 & 0,035716 & \\
\hline 8 & 222 & 19 & 15,475235 & 0,896007 & 0,185124 & \\
\hline 9 & 311 & 11 & 17,854294 & 1,622151 & 0,052385 & \\
\hline 10 & 312 & 16 & 7,461496 & 3,125855 & 0,000886 & Type \\
\hline 11 & 321 & 27 & 27,987812 & 0,186719 & 0,425940 & \\
\hline 12 & 322 & 11 & 11,696399 & 0,203625 & 0,419323 & \\
\hline
\end{tabular}

Berdasarkan hasil analisis, asosiasi diantara variabel ditandai dengan munculnya type atau antitype. Dalam hal ini, munculnya type menjelaskan bahwa terdapat asosiasi diantara variabel prediktor. Kolom pertama menunjukan konfigurasi dari prediktor, ditandai dengan tiga digit angka yang menandakan kriteria berdasarkan pada model (1).

Selanjutnya, analisis antara prediktor dan kriteria dilakukan untuk melihat penyimpangan yang terjadi dengan hasil sebagai berikut:

Tabel 3. Tabel Hasil Statistik Uji Prediktor dan Kriteria

\begin{tabular}{|l|r|}
\hline \multicolumn{1}{|c|}{ Statistik Uji } & \multicolumn{1}{c|}{ Nilai } \\
\hline Chi Kuadrat & 72.0981 \\
\hline Derajat Bebas & 18 \\
\hline$P$-value & $2.220446 \mathrm{e}-16$ \\
\hline
\end{tabular}


Berdasarkan hasil output, nilai $p$-value $\leq \alpha$, yang berarti $H_{0}$ ditolak atau terdapat asosiasi diantara variabel prediktor dan kriteria.

Tabel 4. Tabel Hasil Analisis antara Prediktor dan Kriteria

\begin{tabular}{|c|c|c|c|c|c|c|}
\hline No & Konfigurasi & $\mathbf{N i}$ & $\mathbf{E i}$ & $\mathbf{Z}$ & P-Value & T/A \\
\hline 1 & 1111 & 10 & 4,905232 & 2,300353 & 0,010714 & \\
\hline 2 & 1112 & 14 & 5,807344 & 3,399663 & 0,000337 & Type \\
\hline 3 & 1121 & 2 & 2,049948 & 0,034885 & 0,486085 & \\
\hline 4 & 1122 & 2 & 2,426950 & 0,274060 & 0,392019 & \\
\hline 5 & 1211 & 3 & 7,689283 & 1,691077 & 0,045411 & \\
\hline 6 & 1212 & 4 & 9,103404 & 1,691445 & 0,045375 & \\
\hline 7 & 1221 & 1 & 3,213432 & 1,234757 & 0,108460 & \\
\hline 8 & 1222 & 3 & 3,804408 & 0,412413 & 0,340018 & \\
\hline 9 & 2111 & 5 & 10,816666 & 1,768591 & 0,038481 & \\
\hline 10 & 2112 & 12 & 12,805938 & 0,225214 & 0,410906 & \\
\hline 11 & 2121 & 0 & 4,520398 & 2,126122 & 0,016746 & \\
\hline 12 & 2122 & 2 & 5,351735 & 1,448846 & 0,073690 & \\
\hline 13 & 2211 & 30 & 16,955855 & 3,167785 & 0,000768 & Type \\
\hline 14 & 2212 & 18 & 20,074173 & 0,462941 & 0,321703 & \\
\hline 15 & 2221 & 12 & 7,086029 & 1,845997 & 0,032446 & \\
\hline 16 & 2222 & 7 & 8,389207 & 0,479630 & 0,315745 & \\
\hline 17 & 3111 & 5 & 8,175387 & 1,110561 & 0,133378 & \\
\hline 18 & 3112 & 6 & 9,678907 & 1,182512 & 0,118501 & \\
\hline 19 & 3121 & 3 & 3,416580 & 0,225373 & 0,410844 & \\
\hline 20 & 3122 & 13 & 4,044916 & 4,452612 & 0,000004 & Type \\
\hline 21 & 3211 & 13 & 12,815472 & 0,051546 & 0,479445 & \\
\hline 22 & 3212 & 14 & 15,172340 & 0,300972 & 0,381717 & \\
\hline 23 & 3221 & 3 & 5,355719 & 1,017922 & 0,154357 & \\
\hline 24 & 3222 & 8 & 6,340679 & 0,658965 & 0,254959 & \\
\hline
\end{tabular}

Berdasarkan Tabel 4 di atas, dapat dilihat munculnya type yang menunjukan bahwa terdapat penyimpangan dari base model yang terbentuk. Penyimpangan ini merupakan hasil konfigurasi dari variabel. Kolom pertama menunjukan konfigurasi dari prediktor dan kriteria. Tiga digit angka pertama menunjukan konfigurasi variabel prediktor sedangkan satu digit angka terakhir menunjukan kriteria berdasarkan pada model (2). 


\subsection{Interpretasi Konfigurasi}

CFA memfokuskan pada konfigurasi hasil analisis yang ditandai dengan munculnya type atau antitype. Hasil analisis tersebut menunjukan bahwa model konfigurasi tersebut signifikan. Adapun, konfigurasi yang tidak muncul type atau antitype-nya menjelaskan bahwa konfigurasi tersebut sudah sesuai dengan base model. Berdasarkan hasil analisis data, type muncul pada tiga konfigurasi berikut:

1. 1112 : karakteristik untuk responden dengan pekerjaan sebagai pelajar/mahasiswa, dengan pengeluaran per bulan kurang dari atau sama dengan Rp 1.250.000,00, pengguna sepeda motor, dan memiliki Top Of Mind Kompetitor.

2. 221 1: karakteristik untuk responden dengan pekerjaan sebagai karyawan (PNS/swasta), dengan pengeluaran per bulan lebih dari Rp 1.250.000,00, pengguna sepeda motor, dan memiliki Top Of Mind sepeda motor $\mathrm{X}$.

3. 312 2: karakteristik untuk responden dengan pekerjaan lainnya (wiraswasta), dengan pengeluaran per bulan kurang dari atau sama dengan Rp 1.250.000,00, calon pengguna sepeda motor, dan memiliki Top Of Mind Kompetitor.

\section{KESIMPULAN}

Berdasarkan hasil analisis yang telah dilakukan, dapat disimpulkan bahwa Pada Configural Frequency Analysis (CFA), base model yang dibuat berdasarkan model Log Linier diasumsikan tidak dapat menjelaskan data dengan baik, maka analisis difokuskan pada ketidak cocokkan antara base model dengan data. Ketidak cocokkan tersebut diperlihatkan dengan munculnya type atau antitype dan terdapat tiga karakteristik yang menyimpang berdasarkan munculnya type pada hasil analisis. Type menunjukan bahwa karakteristik yang menyimpang tersebut sering terjadi daripada yang diharapkan. Karakteristik yang telah ditentukan tersebut perlu diperhatikan secara khusus dan menjadi rekomendasi untuk menentukan strategi selanjutnya dalam mempertahankan dan meningkatkan Top of Mind 


\section{DAFTAR PUSTAKA}

Agresti, A., An Introductional to Categorical Analysis, John Willey \& Sons, Inc., New York, 2007.

Agung, I. G. N., Analisis Hubungan Kausal Berdasarkan Data Ketegori, PT Raja Grafindo Persada, Jakarta, 2002.

Dobson, A. J., Introduction to Statistical Modelling. Chapman and Hall Ltd: Londonv, 1983.

Durianto, Brand Equity Ten Strategi Memimpin Pasar, Penerbit P. T.Gramedia Pustaka Utama, Jakarta, 2004.

Johnson, R. A., dan Wichern, D. W., Applied Multivariate Statistical Analysis, Edisi Kelima, Prentice Hall Inc., New Jersey, 2002.

Kotler, P. dan Keller, K. L., Manajemen Pemasaran, PT Indeks, Jakarta, 2008.

Peter, P. J. dan Olson, J. C., Consumer Behavior and Marketing Strategy, Edisi Keempat, Richard D. Irwin Inc., 1996.

Pontoh, R. S. Configural Frequency Analysis untuk Melihat Karakteristik Calon Investor Potensial PT. Bursa Efek Indonesia di Jawa Timur. Makalah yang di presentasikan pada Seminar Nasional Penelitian, Pendidikan, dan Penerapan MIPA, Yogyakarta, 2009.

Von Eye, A. Configural Frequency Analysis: Methods, Models, and Aplications, Lawrence Erlbaum Associates, London, 2002. 
